\title{
Performance Comparison of AODV and CAODV Routing Protocol using Cognitive Radios
}

\author{
Pratibha $^{1}$, Shilpa Srivastava Khare ${ }^{2}$ and Shailender Gupta ${ }^{3}$ \\ ${ }^{1}$ Amity School of Engineering and Technolog \\ ${ }^{2}$ ECE Department, Noida, India \\ ${ }^{3} Y M C A$ University of Science and Technology, /ECE Department, Faridabad, India \\ ${ }^{1}$ prati.tewatia741@gmail.com, ${ }^{2}$ sskhare@amity.edu, ${ }^{3}$ shailender81@gmail.com
}

\begin{abstract}
The Cognitive Radio (CR) technology has evolved in the recent past to solve the problem of wireless networks resulting from the limited available spectrum. The networks employing cognitive radios are termed as Cognitive Radio Ad hoc Networks (CRAHN). These networks employ: Primary Users (PUs) and Secondary Users (SUs), PU is the one that have licensed band while the $S U$ uses the licensed band of PU opportunistically for communication purpose. To have communication in CRAHN, a routing protocol is required. The performance of this protocol depends upon various factors such as: mobility, transmission range, number of nodes deployed and environment. This paper is an effort to measure the efficacy of routing protocol by varying the above mentioned factors. For this purpose we implemented a Cognitive Ad hoc On demand Distance Vector (CAODV) routing protocol in MATLAb-09. Moreover, this paper also shows the advantage of CAODV over the standard protocol AODV.
\end{abstract}

Keywords: CRAHN; Routing protocol; On-demand routing; AODV

\section{Introduction}

The use of Cognitive Radios (CR) [1-2] in recent past has gained popularity due to its spectrum sensing capability and dynamically adaptation of their transmission waveforms. Hence, CRs have potential to increase the spectrum utilization. Basically we have two types of users in CRAHN named as PU and SU [3-5].

- Primary User (PU) is the one that use licensed band for the purpose of communication.

- Secondary User (SU) tries to use PUs opportunistically (when PU is free) for its communication.

In case the PUs doesn't permit the SU for communication the performance of network significantly deteriorates. The communication in CRAHN is achieved with the help of routing protocol whose main purpose is to establish a route from source to destination. Various routing protocols have been proposed in literature whose performance depends upon various factors as follows:

- Transmission Range: It is an important factor that affects the routing protocol performance, when its value is high; it helps in having packet delivery ratio and reachability value but at the same time results in over consumption of resources such as battery power, as depletion of battery power is directly proportional to transmission range [6-11]. On the other hand when transmission range is low, it 
results in lower value of packet delivery ratio and reachable paths, which is not a desirable feature in MANET.

- Number of nodes [6]: This factor when too low results in lower packet delivery ratio and reachability value and when too high results in unnecessary wastage of resources.

- Mobility [12-16]: CRAHN performance is significantly reduced when the nodes speed is too high i.e. as the nodes speed increases the number of link failures increase resulting in lower values of reachability value and packet delivery ratio.

- Environment: Another factor that hinders the CRAHN performance is the environment in which the nodes are deployed. The environment may contain unpredictable obstacles, such as lakes, mountains etc. These obstacles not only restrict nodes movement but may obstruct the effective transmission paths between nodes [17-18].

We are of the opinion that if a routing protocol is to be developed then it must take into consideration the following factors mentioned above so that we can achieve high value of reachability and packet delivery ratio. In this paper the efficacy of CAODV routing protocol is evaluated by varying the above mentioned factors. The paper also shows the advantage of CAODV [19-20] over AODV [21] protocol used for ad hoc network.

The rest of the paper is organized as follows: Section 2 provides a brief description of AODV and CAODV protocol used in this paper. Section 3 gives the simulation set up parameters and performance metrics used to evaluate the performance of the protocols used. Section 4 gives the results obtained by varying various factors mentioned above followed by conclusion and references.

\section{Routing Protocol under Consideration}

Before discussing the CAODV protocol a brief description of AODV is required for its better understanding.

\subsection{Ad Hoc on Demand Distance Vector (AODV)}

The Working of AODV [21] protocol can be divided into three phases Route Request, Route Reply and Route maintenance phase. All these three phases are discussed as follows:

\section{Route Request Phase}

In this phase, when a source node wishes to communicate with a distant node whose route is not available, it initiates a route discovery operation. The source node floods route request (RREQ) packets as shown in Figure 1 until it reaches to destination or to a node which has information about the destination node. To reduce the flooding overhead, a node discards RREQs that it has seen before. Each node maintains a cache to keep track of RREQs it has received. The cache also stores the path back to each RREQ originator.

\section{Route Reply Phase}

In this phase, all RREQs reach to destination node. The destination node now checks the path having minimum number of hop (intermediate nodes). The packet having minimum hop count value is used to construct the reverse path. The destination node generates a Route Reply (RREP) packet and unicast it to the source node using the path having minimum hop count as also shown in Figure 2. 


\section{Route Maintenance Phase}

In AODV, a node uses hello messages to notify its existence to its neighbors. Therefore, the link status to the next hop in an active route can be monitored. When a node discovers a link disconnection, it broadcasts a Route Error (RERR) packet to its neighbors, which in turn propagates the RERR packet towards nodes whose routes may be affected by the disconnected link. Then, the affected source can re-initiate a route discovery operation if the route is still needed.

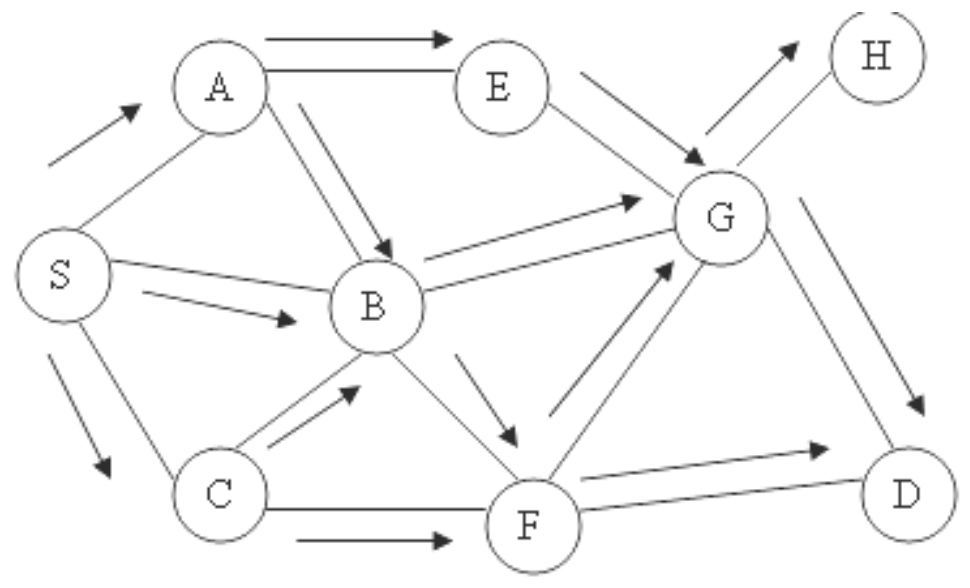

Figure 1. Flooding RREQ in AODV

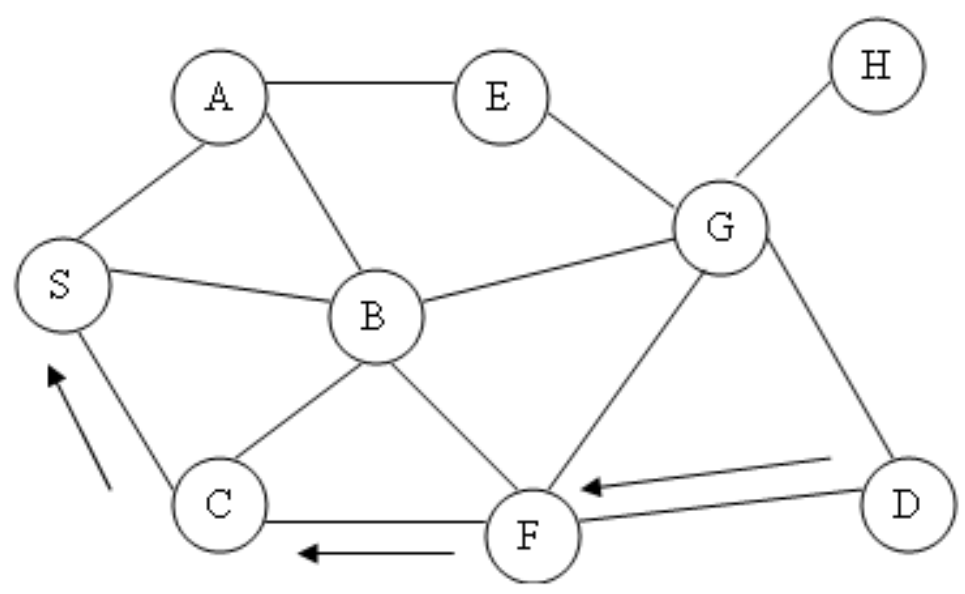

Figure 2 Route Reply in AODV

\subsection{CAODV}

Minor modifications are needed to convert the standard on demand AODV to CAODV [20]. The modifications are as follows:

- Whenever a node needs route to destination, it broadcast RREQ by amending spectrum related information in it. The spectrum related information includes best free available channel.

- An intermediate (SU) node that receives RREQ checks whether it is in contact with a PU. If yes, then it simply adds information about the free spectrum and 
broadcast the packet further till it reaches to destination or to an intermediate node that has information about the destination as well as of spectrum in its routing table. In case no free channel is available then it simply drops the RREQ as shown in Figure 3.

- The destination node chooses the best possible path by taking best shortest path from all feasible paths that it receives.

This small minor modification is done in our code to make CAODV protocol for CRAHN. The next section gives the simulation set up parameters used in our experiment.

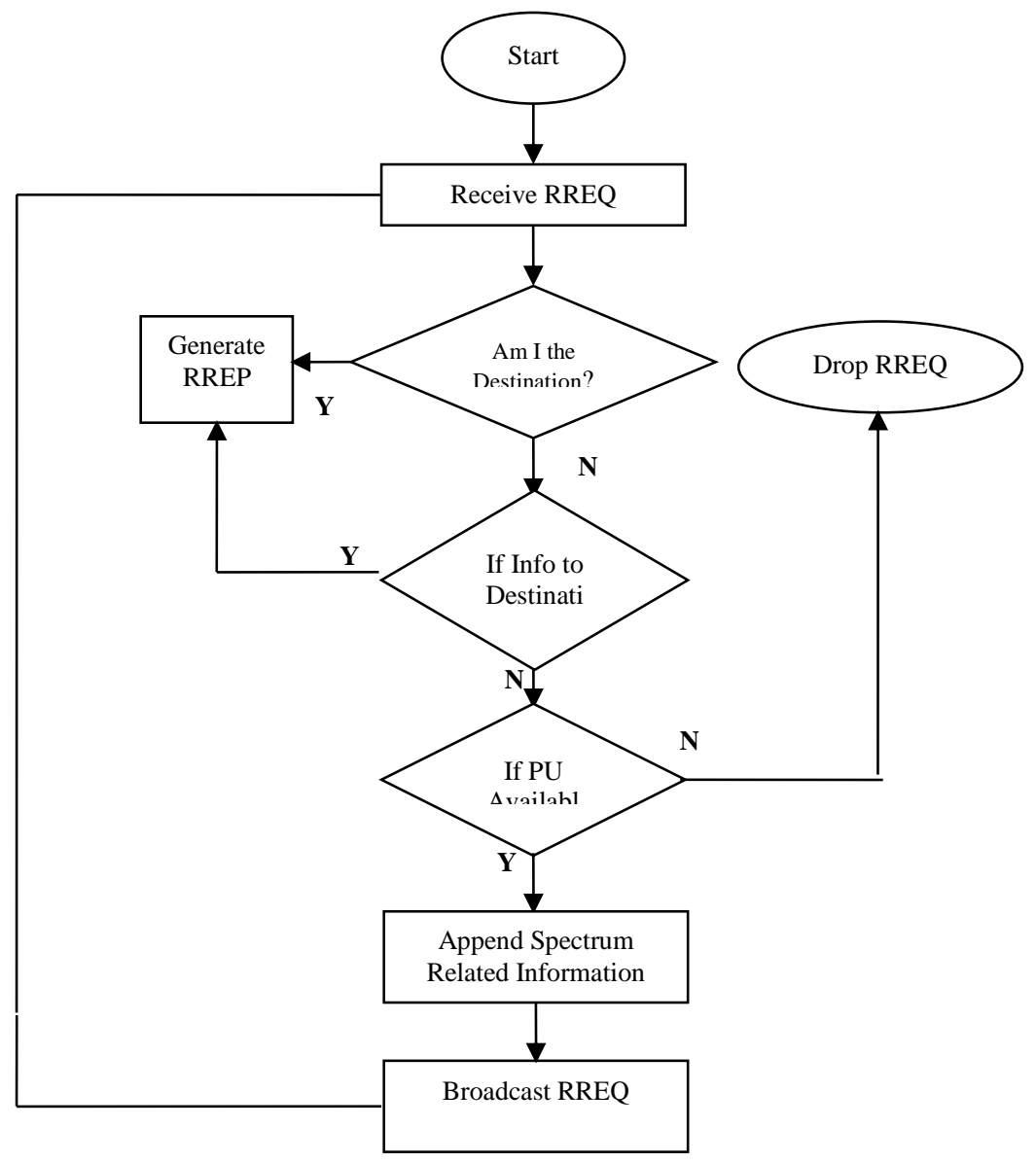

Figure 3. Modification in Route Request Phase (Intermediate Node)

\section{Simulation Set up Parameters}

This section gives the set up parameters flowchart used for calculation of results in our experiments. 


\subsection{Set up Parameters}

The following set up parameters is used for simulation purpose:

Table 1. Setup Parameters

\begin{tabular}{|c|c|c|c|}
\hline $\begin{array}{l}\text { Set up } \\
\text { parameter }\end{array}$ & Value & $\begin{array}{l}\text { Set up } \\
\text { parameter }\end{array}$ & Value \\
\hline $\begin{array}{l}\text { Area of } \\
\text { simulation } \\
\text { Region }\end{array}$ & $\begin{array}{l}2000 \times 2000 \\
\text { sq units }\end{array}$ & $\begin{array}{l}\text { PU Nodes } \\
\text { Position/ SU } \\
\text { Nodes } \\
\text { Position }\end{array}$ & $\begin{array}{l}\text { Fixed/ } \\
\text { Random }\end{array}$ \\
\hline $\begin{array}{l}\text { Number of SU } \\
\text { nodes }\end{array}$ & $\begin{array}{l}\text { Varied from } \\
24 \text { to } 42, \text { step } \\
\text { size of } 6\end{array}$ & $\begin{array}{l}\text { Routing } \\
\text { algorithm }\end{array}$ & $\begin{array}{l}\text { Optimal path } \\
\text { determination }\end{array}$ \\
\hline $\begin{array}{l}\text { Numbers of } \\
\text { PU nodes }\end{array}$ & 16 & $\begin{array}{l}\text { Packet } \\
\text { transmission } \\
\text { interval }\end{array}$ & $.09 \mathrm{sec}$ \\
\hline $\begin{array}{l}\text { Transmission } \\
\text { Range }\end{array}$ & $250-350 \mathrm{~m}$ & Packet Size & 512 bytes \\
\hline $\begin{array}{l}\text { Mobility } \\
\text { Model }\end{array}$ & $\begin{array}{l}\text { Random } \\
\text { Walk } \\
\end{array}$ & $\begin{array}{l}\text { Number of } \\
\text { packet sent }\end{array}$ & 130 \\
\hline $\begin{array}{l}\text { PU nodes } \\
\text { mobility }\end{array}$ & $\begin{array}{l}\text { NIL, PU } \\
\text { nodes are } \\
\text { fixed }\end{array}$ & $\begin{array}{l}\text { Channels } \\
\text { available } \\
\text { With each PU }\end{array}$ & 4 \\
\hline $\begin{array}{l}\text { Speed of SU } \\
\text { nodes }\end{array}$ & $5-15 \mathrm{~m} / \mathrm{s}$ & $\begin{array}{l}\text { Total Time } \\
\text { allotted for } \\
\text { transmission } \\
\text { of all Packets }\end{array}$ & $360 \mathrm{msec}$ \\
\hline $\begin{array}{l}\text { Number of } \\
\text { obstacles In } \\
\text { realistic case }\end{array}$ & 2 & $\begin{array}{l}\text { Type of the } \\
\text { obstacles- } \\
\text { Shape of } \\
\text { Obstacle - }\end{array}$ & $\begin{array}{l}\text { Mountain type } \\
\text { Rectangle }\end{array}$ \\
\hline
\end{tabular}

\subsection{Performance Metrics}

The following performance metrics were taken into consideration.

- Hop Count- Defined as the number of intermediate hops from source to the destination.

- Probability of Reach ability (PoR) - Defined as the ratio of total paths actually formed in the cognitive network to the total number of possible paths.

- Delay-Defined as the difference in the transmission time when the data is transmitted through optimized path and when data is transmitted though the un optimized or the shortest path to the total number of paths actually formed in the network 


\subsection{Algorithm Used for Results Calculation}

The algorithm shown under is used for calculation of results:

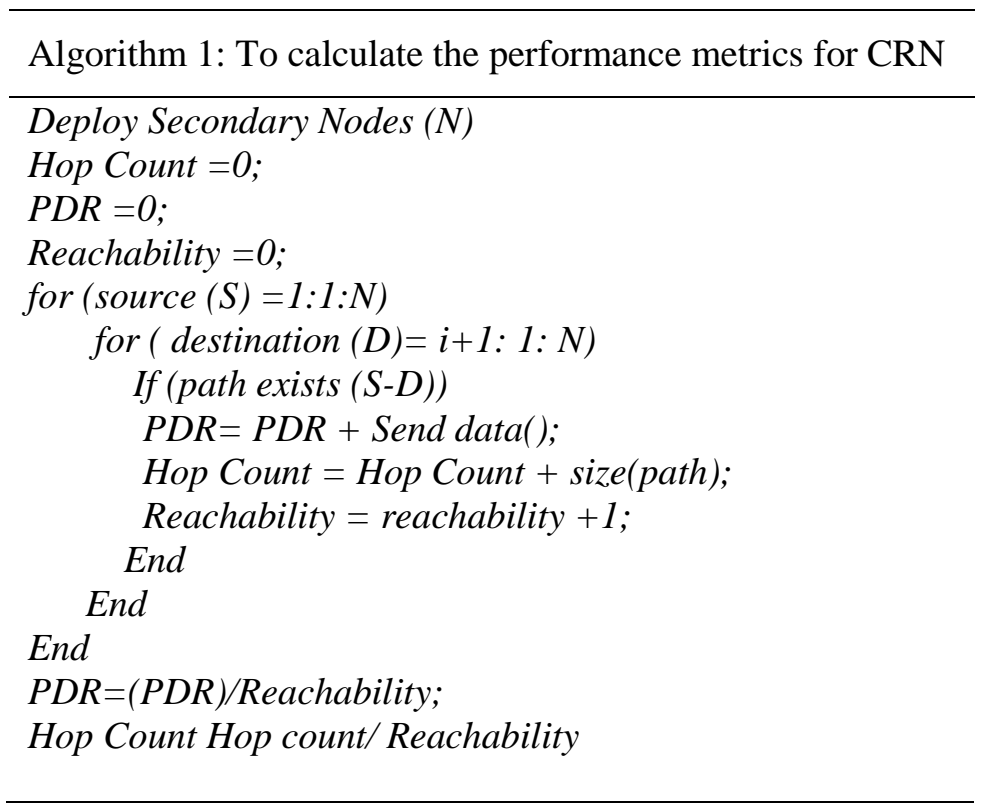

\subsection{Snapshots}

Figure 4 and Figure 5 show the snapshots of the simulation process for idealistic and realistic scenarios. The red numbered dots shown in both the figures represent the PU Ids while the black numbered dots represent the SU. The green line shows the path from source to destination in both the figures. Figure 5 shows the green rectangular obstacles that not only restricts nodes movement but also hinders the effective transmission range of the nodes.

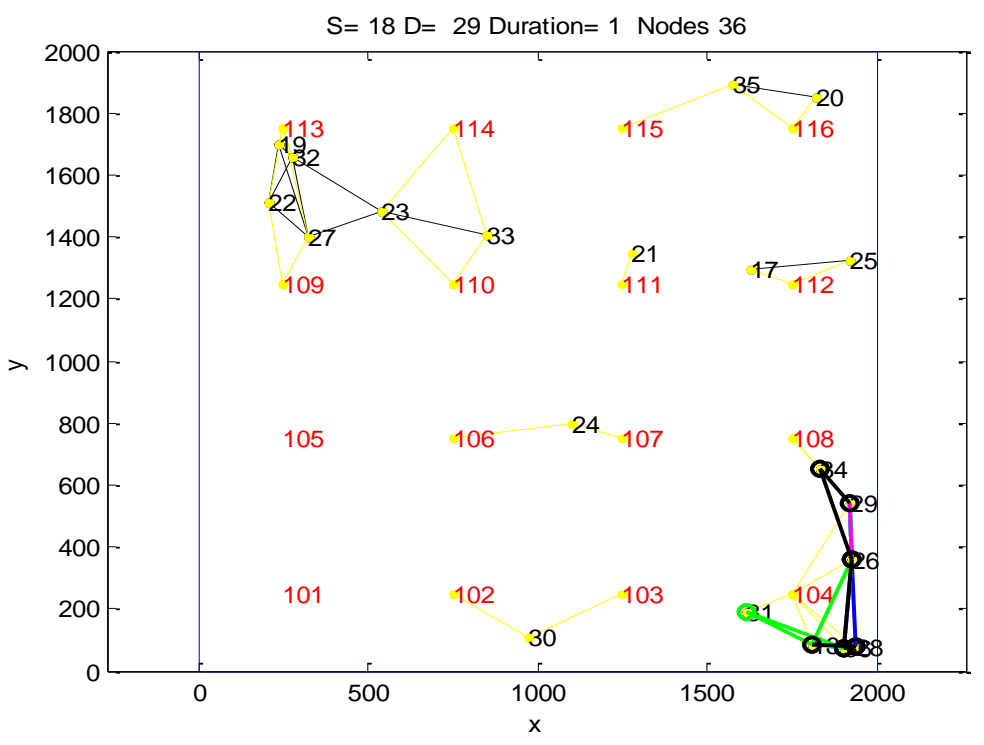

Figure 4. Snapshot of Simulation Process (Idealistic Scenario) 


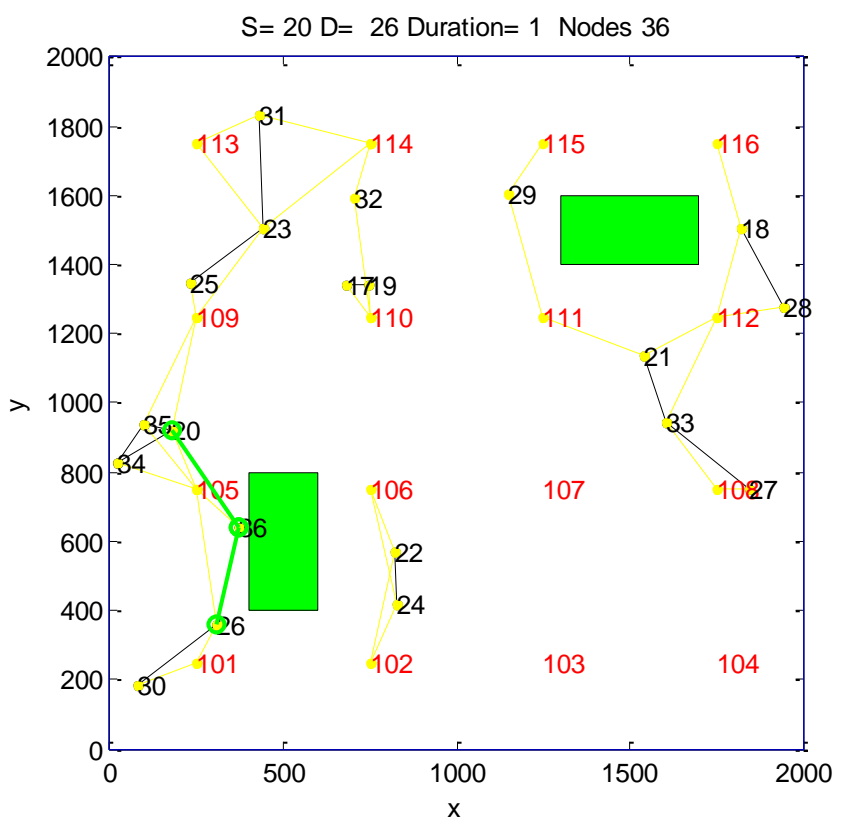

Figure 5. Snapshot of Simulation Process (Realistic Scenario)

\section{Results}

\subsection{Impact of Transmission Range on CRAHN}

Figure 6 shows the impact of transmission range on CRAHN performance. The following inference can be drawn from the results:

- The value of PDR increases while that of hop count and delay decreases with increase in transmission ranges value. The reason for the same is the increase in the value of neighbor node density with increase in transmission range.

- It should be noted that transmission range though increase the PDR value but at the same time results in over consumption of battery power. Hence it should be utilized in an efficient manner.

- The value of all the performance metrics is better for CAODV which considers spectrum availability in comparison to shortest path routing protocol which doesn't consider so.

\subsection{Impact of Mobility on CRAHN}

Figure 7 shows the impact of speed on CRAHN performance. The following inference can be drawn from the results:

- As the speed of nodes increases the number of path breakage increase hence the value of PDR and hop count decreases while that of delay increases.

- The static AODV which doesn't use any mobility model has same performance at all speed levels as can be seen from the graphs. 

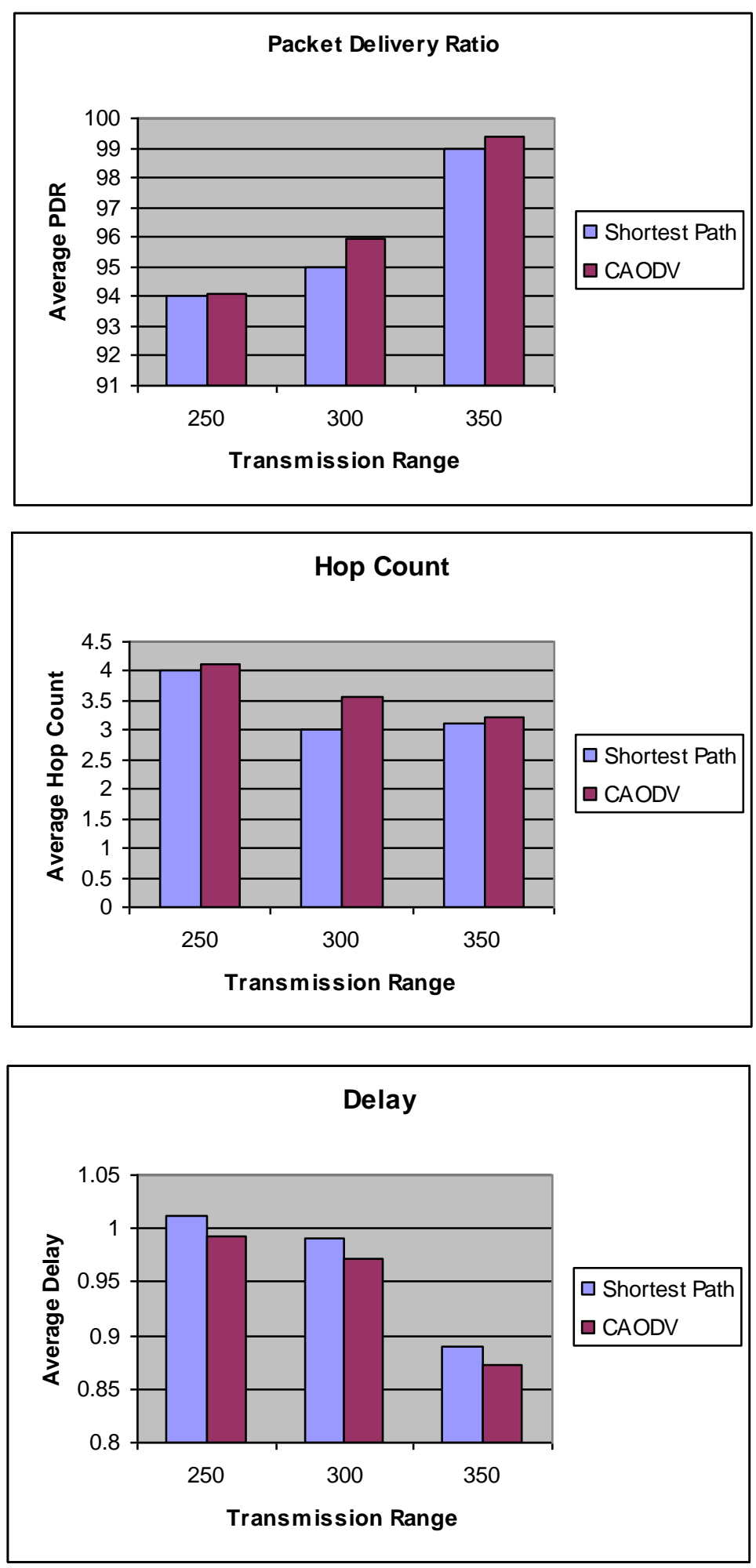

Figure 6. Impact of Transmission Range 


\subsection{Impact of Environment}

Table 2 shows the impact of environment that is obstacle on the performance of CAODV. It can be observed that the obstacles decrease the value of hop count and packet delivery ratio in comparison to a scenario that contains no obstacle. The reason for the same is the reduction in feasible paths due to obstruction by the obstacle.

Table 2. Impact of Obstacles

\begin{tabular}{|l|r|r|}
\hline Parameter & CAODV With 2 obstacle & CAODV with no obstacle \\
\hline PDR & 96.332 & 98.67782 \\
\hline HOPCOUNT & 4 & 3 \\
\hline DELAY & 0.164427 & 0.1216 \\
\hline
\end{tabular}
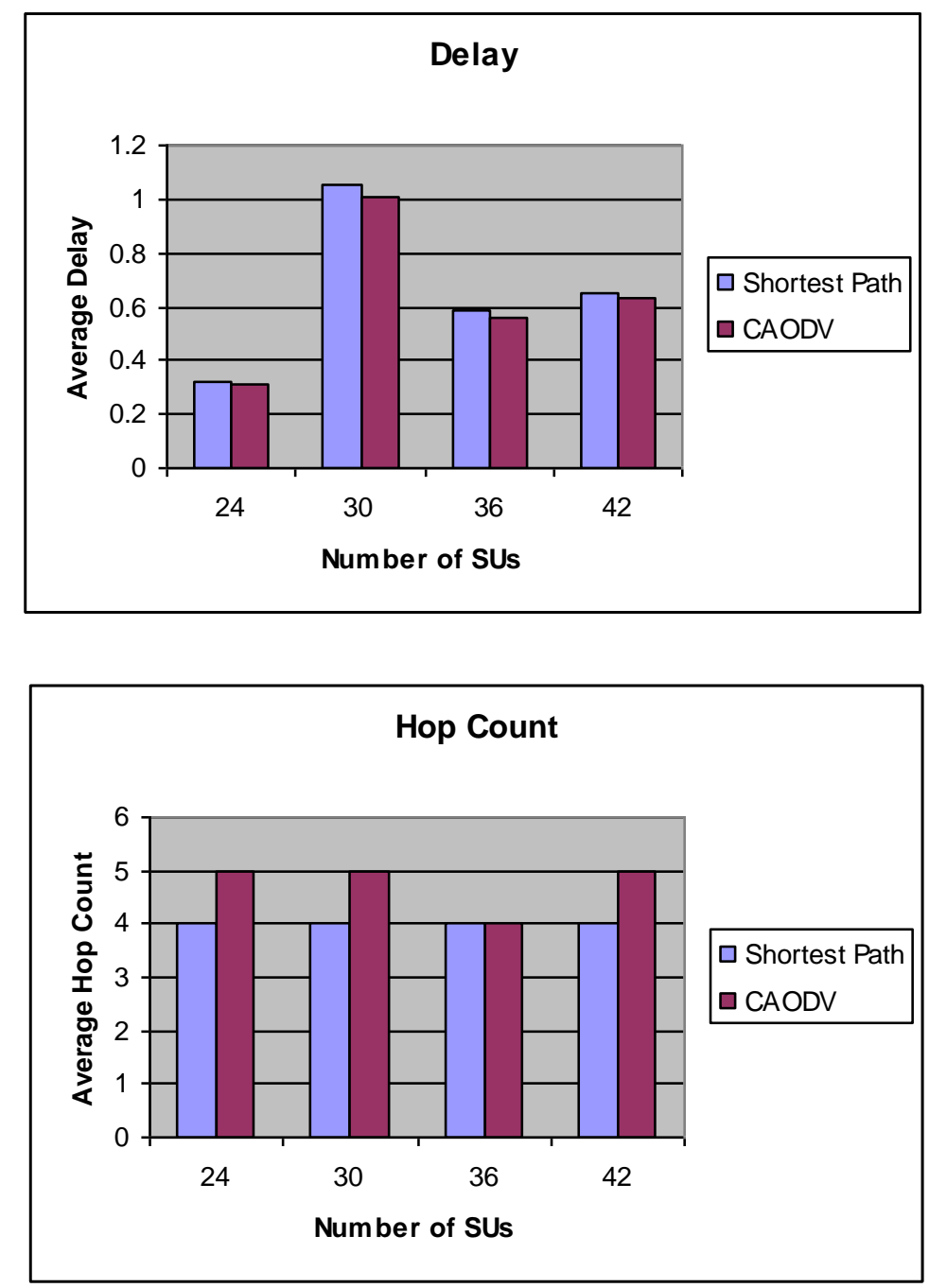


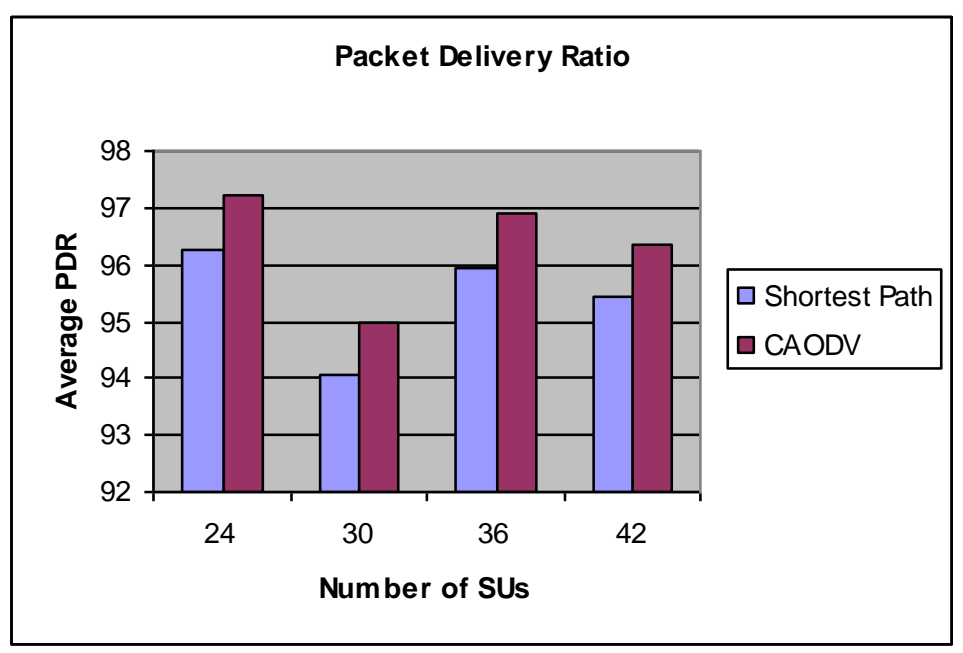

Figure 7. Impact of Speed

\subsection{Impact of Number of Nodes}

Figure 8 shows the variation of number of secondary users on CRAHN performance. The following inference can be drawn from the results:

- As the number of secondary nodes increases there is no effect in performance of shortest path or CAODV since for communication purpose we require free channel of PU only.

- The performance of CAODV is better for all concentration of SU nodes is better then shortest path routing protocol since it considers spectrum availability.

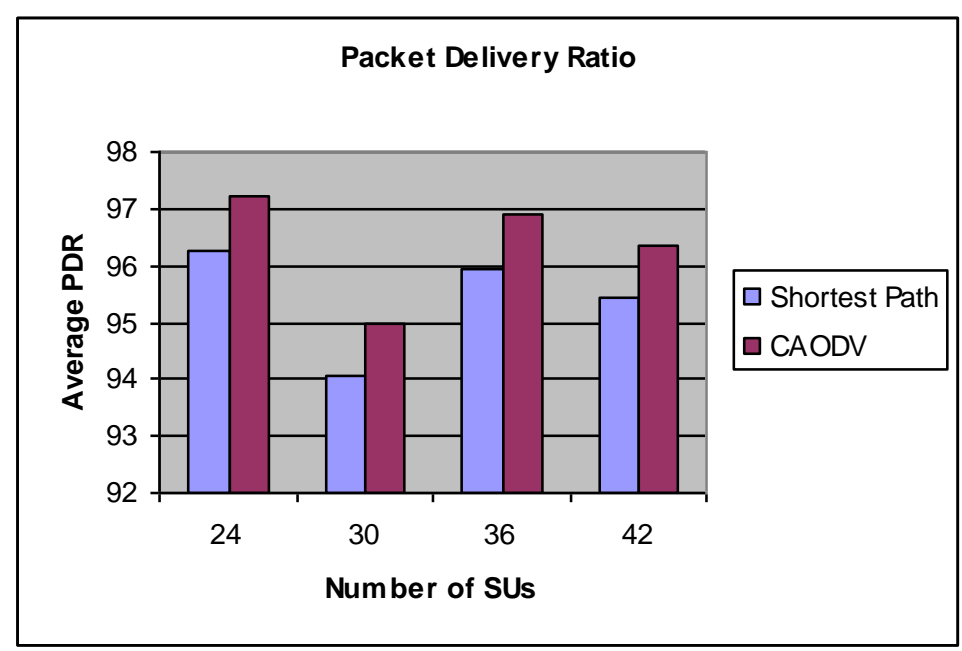



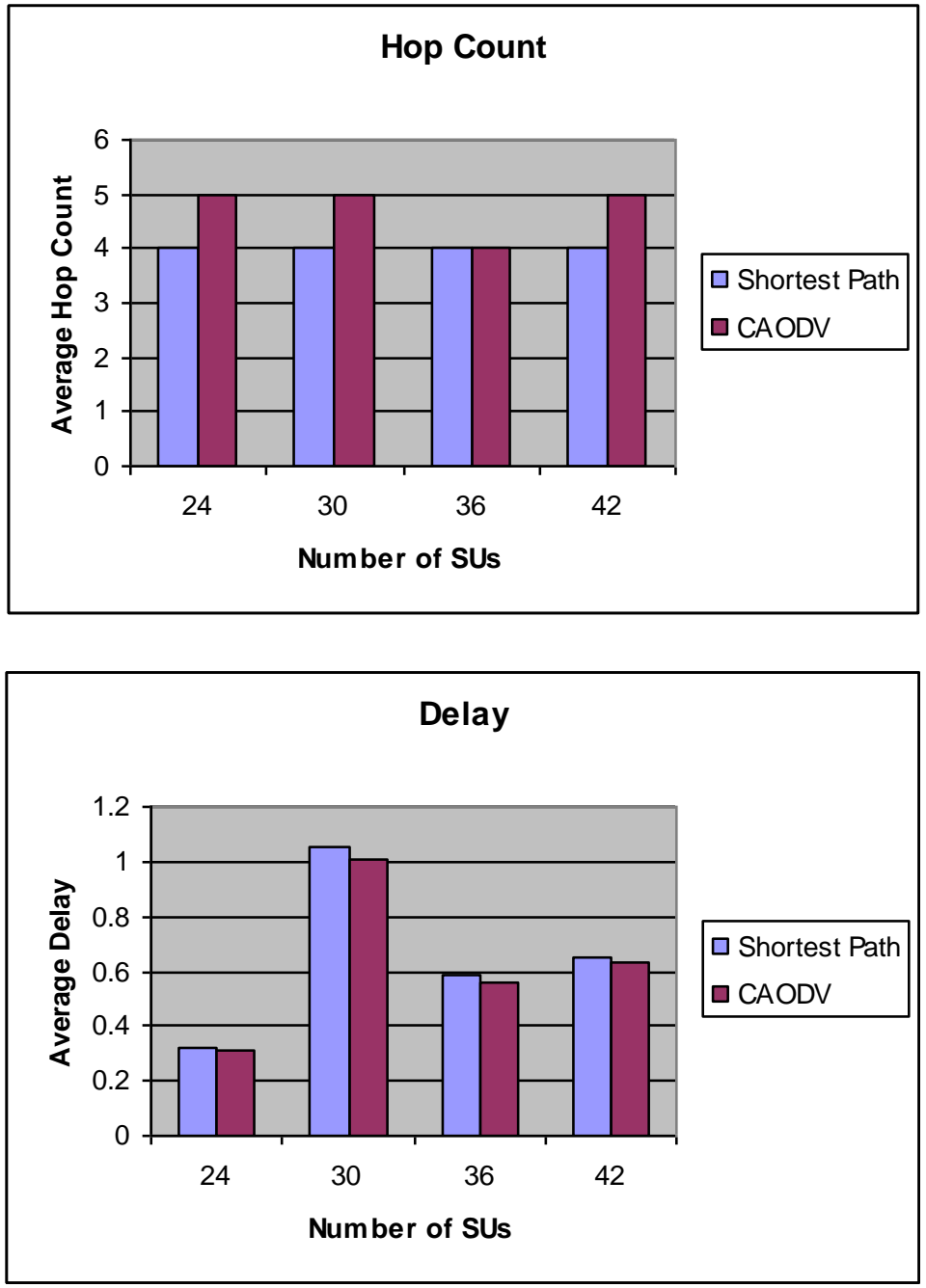

Figure 8. Impact of Number of Secondary Users

\section{Conclusion}

This paper considers a routing protocol for cognitive radio network. The paper evaluates the performance of CAODV by varying speed, transmission range, number of secondary users and environment. The following important conclusion can be drawn as follows:

- The transmission range, environment and mobility influence the performance of CAODV very much as can be observed from the results.

- The CAODV protocols performance is better in comparison to shortest path routing protocol for all performance metrics.

- If delay and other factors such as residual power is considered then CAODV performance can be enhanced further.

- This paper also shows that ad hoc routing protocol does not efficiently utilize the spectrum as CRAHN protocol.

The results can be very fruitful for researchers working in this direction. 


\section{Acknowledgement}

The authors would like to thanks Sh. S. B. Gupta and Dr. R.K. Tewatia for their continuous moral and emotional support to finish this project.

\section{References}

[1] Y.-C. Liang, K. C. Chen and Geoffrey, "Cognitive Radio Networking and Communications: An Overview", Published in IEEE Transactions on Vehicular Technology, vol. 60, no. 7, (2011) September.

[2] S. M. Kamruzzaman, E. Kim and D. G. Jeong, "An Energy Efficient QoS Routing Protocol for Cognitive Radio and Ad Hoc Networks", Published in International Conference on Advance Communication Technology (ICACT), (2011), pp.344-349.

[3] Y.-S. Chen and S. H. Liao, "Spectrum-aware Routing in Discontinuous Orthogonal Frequency Division Multiplexing-based CR Ad Hoc Networks", Published in IET Networks, vol.1, (2012), pp.20-33.

[4] A. C. Talay and D. T. Altilar, "United Nodes: Cluster Based Routing Protocol for Mobile Cognitive Radio Networks", Published in IET Communications, vol. 5, no. 15, (2011) June, pp. 2097-2105.

[5] V. Kukreja, S. Gupta, B. Bhushan and C. Kumar, "Towards Performance Evaluation of Cognitive Radio Network in Realistic Environment”, IJCNIS, vol. 6, no. 1, (2014), pp. 61-77.

[6] F. Ingelrest, D. S. Ryl and I. Stojjmenovic, "Optimal Transmission Radius for Energy Effiecinet Broadingcasting Protocol in Ad-hoc and Sensor Networks", IEEE Transactions on Parallel and Distributed Systems, vol. 17, no. 6, (2006) June.

[7] F. J. Ovalle-Martinez, I. Stojmenovic, F. Gracia-Nocetti and J. Solano-Gonzalez, "Finding minimum transmission radii for preserving connectivity and constructing spanning trees in ad-hoc sensor networks", Journal of Parallel and Disributed Computing, vol. 2, (2005), pp. 132-141.

[8] C. K. Nagpal, M. Kaur, S. Gupta and B. Bhushan, "Impact Of Variable Transmission Range On Manet Performance", International Journal of Ad hoc, Sensor \& Ubiquitous Computing (IJASUC), vol. 2, no. 4, (2011) December.

[9] C. Kumar, S. Gupta and B. Bhushan, "Impact Of Various Factors On Probability Of Reachability In Manet: A Survey", International Journal on Applications of Graph Theory in Wireless ad Hoc Networks and Sensor Networks (GRAPH-HOC), vol. 3, no. 3, (2011) September.

[10] D. Bein, A. K. Datta, P. Sajja and S. Q. Zheng, "Impact of Variable Transmission Range in All-Wireless Networks", Proceedings of the 42nd Hawaii International Conference on System Sciences, (2009).

[11] J.-P. Shew, K.-Y. Hsieh and Y.-K. Cheng, "Distributed Transmission Power Control Algorithm for Wireless Sensor Networks", Journal of Information Science and Engineering, vol. 25, (2009), pp. 1447-1463.

[12] T. Camp, J. Boleng and V. Davies, "A Survey of Mobility Models for Ad Hoc Network Research", Wireless Communication \& Mobile Computing (WCMC): Special Issue on Mobile Ad Hoc Networking: Research, Trends and Applications, vol. 2, no. 5, (2002), pp. 483-502.

[13] B. Divecha, A. Abraham, C. Grosan and S. Sanyal, "Impact of Node Mobility on MANET Routing Protocols Models", Journal of Digital Information Management, (2007) February.

[14] N. Cooper and N. Meghanathan, "Impact of Mobility Models in Multi-Path Routing in Mobile Ad Hoc Networks", International Journal Of Computer Networks \& Communications (IJCNC), vol. 2, no.1, (2010) January.

[15] A. Jardosh, E. M. B. Royer, K. C. Almeroth and S. Suri, "Towards Realistic Mobility Models For Mobile Ad hoc Networks", Proceedings of MobiCom, San Diego, California, USA, (2003) September.

[16] C. Kumar, C. K. Nagpal, B. Bhushan and S. Gupta, "Reachability Analysis of Mobility Models under Idealistic and Realistic Environments", Proceedings by Springer, (2012).

[17] A. Jardosh, E. M. B. Royer, K. C. Almeroth and S. Suri, "Real world Environment Models for Mobile Ad hoc Networks", IEEE Journal on Special Areas in Communications - Special Issue on Wireless Ad hoc Networks, vol. 23, (2005), pp. 622-632.

[18] C.-Y. Chang, C.-T. Chang and S.-C. Tu, "Obstacle-Free Geocasting Protocols for Single/Multi-Destination Short Message Services in Ad Hoc Networks", Wireless Networks, vol. 9, (2003), pp. 143-155.

[19] S. Salim and S. Moh, "On-demand Routing Protocols for Cognitive Radio ad hoc Networks", EURASIP Journal on Wireless Communications and Networking, vol. 1, (2013), pp. no. 1-10.

[20] A. S. Cacciapuoti, M. Caleffi and L. Paura, "Reactive Routing for Mobile Cognitive Radio ad Hoc Networks" ACM Digital Library, vol. 10, no. 5, (2012), pp. no. 803-815.

[21] C. Perkins and E. B. Royer, "Ad Hoc On-demand Distance Vector (AODV) Routing", IETF RFC 3561, (2003). 